\title{
EFFECT OF IMPLANT ANGULATION AND TRAY TYPE ON DIMENSIONAL ACCURACY OF OPEN TRAY IMPLANT IMPRESSIONS
}

\author{
Hayat I. Mahrous *, Ghada I. Shehab ${ }^{* *}$ and Hanaa I. Sallam***
}

\begin{abstract}
Statement of the problem: Impression making is a critical clinical step to record accurately the three-dimensional intraoral relationships among implants, teeth and adjacent structures. Inaccuracy during impression making inevitably leads to laboratory errors resulting in lack of precision and misfit of the final prostheses. Several clinical variables may affect the precision of impression particularly in the presence of multiple angulated implants.
\end{abstract}

Purpose: The aim of this study was to evaluate the effect of implant angulation and tray type on dimensional accuracy of open tray implant impressions.

Materials and methods: A unilateral free end saddle dentate acrylic maxillary model resembling Kennedy class II starting from a missing canine was used in this study. Three models were duplicated from the acrylic model into epoxy resin master models. In each model, three implants were inserted in the sites of missing canine, second premolar and second molar. According to the direction of implant insertion, the master models were classified into three groups: Group 1: The three implants were inserted with $0^{\circ}$ angulation (straight, control group). Group 2: The three implants were inserted with $15^{\circ}$ angulation. Group 3: The three implants were inserted with $25^{\circ}$ angulation. For all groups, open tray impressions were taken. Impressions of each group were subdivided according to the tray type into two subgroups: Subgroup A: Open tray impressions using custom made trays. Subgroup B: Open tray impressions using ready-made trays. All impressions were poured with type IV dental stone to obtain stone casts. Dimensional accuracy of the impressions was assessed using the travelling microscope. Reference distances were measured by standardized measurement protocol on the stone casts and compared with similar distances in the master models.

Results: The results showed that there was a statistically significant difference between the three implant angulations. $25^{\circ}$ angulation showed the highest mean of dimensional changes while, there was no statistically significant difference between $0^{\circ}$ and $15^{\circ}$ angulations in dimension II and III ( $\boldsymbol{P}$ value $=0.009 \&<0.001$ respectively). Regarding the effect of tray type, the results showed that there was statistically significant difference in dimensional changes and the percent of dimensional changes between the two tray types in dimension III $(\boldsymbol{P}$ value $=0.019)$. Custom made tray showed statistically significant higher dimensional changes compared to ready-made tray.

Conclusions: Impressions with ready-made trays showed less dimensional changes in case of $25^{\circ}$ angulated implants.

KEY WORDS: Implant angulation, Impression accuracy, Open tray implant impression, Tray typ

* Demonstrator of Fixed Prosthodontics, Faculty of Oral and Dental Medicine, Cairo University, Egypt.

** Professor of Fixed Prosthodontics, Faculty of Oral and Dental Medicine, Cairo University, Egypt.

*** Assistant Professor of Fixed Prosthodontics, Faculty of Oral and Dental Medicine, Cairo University, Egypt. 


\section{INTRODUCTION}

Dental implants have provided alternative treatments to conventional prostheses for partially and completely edentulous patients. The use of dental implants has greatly broadened the scope of clinical dentistry, creating additional treatment options in complex cases in which functional rehabilitation was previously limited or inadequate. Years of clinical experience have fostered a consensus regarding many of the placement criteria and techniques to maximize the chance for longterm implant stability and function. ${ }^{(1)}$

Ideally, implants should be placed parallel to each other, as well as, to adjacent teeth and be aligned vertically with axial forces. However, achieving this may not be possible owing to deficiencies in the ridge's anatomy. ${ }^{(2)}$ The position of the mandibular canal and ridge proximity to the paranasal and maxillary sinuses are additional factors that may influence implant placement. ${ }^{(3)}$

One attractive approach when treating the posterior maxilla is to use tilted implants to engage as much cortical bone as possible. The use of tilted implants in the residual crestal bone permits placement of longer implants, which increases the degree of implant-to-bone contact area and also the implant primary stability. ${ }^{(4)}$

The passive fit of implant retained prosthesis is an important factor in the success of oral rehabilitation procedures. The absence of passive fit may lead to mechanical failures such as; screw bending, screw loosening or fracture, as well as, biological failures in the form of loss of osseointegration and increased plaque accumulation ${ }^{(5)}$.

Precise working casts are needed to fabricate passively fitting implant supported prosthesis. Accurate implant impressions play a significant role and serve as a starting point in the process of fabrication of accurate working casts ${ }^{(5,6)}$.

There are many factors affecting the accuracy of implant impressions such as; the implant impression technique either direct (open tray, pick-up) or indirect (closed tray, transfer), type of impression material, type of impression tray used, type and surface treatment of impression transfer copings and their splinting, as well as, the direction of implants, being straight or angulated ${ }^{(7,8)}$.

The lack of parallelism in implants creates an undesirable path of withdrawal that may distort the impression material upon removal, producing an inaccurate master cast, especially with the closed tray technique ${ }^{(9)}$. When multiple implants are surgically placed at different angles, the distortion of the impression material upon tray removal may increase ${ }^{(9)}$. Also, this effect may be heightened by an increasing number of implants ${ }^{(10)}$.

Assunção et al (2007) ${ }^{(11)}$ evaluated the influence of implants inclination on the accuracy of the working cast obtained by two different pouring techniques and found that perpendicular implants produced more accurate casts independently of the plaster pouring technique.

Kempler (2011) ${ }^{(9)}$ measured the accuracy of implant impression techniques in vitro, using open and closed tray techniques with internal and external connection implants at various angulations $(0,15$ and 30 degrees). They concluded that when encountering full arch implant restorations it is most beneficial to have the implants as parallel to each other as possible and to remove the custom tray along the same path as the implant angulation.

Mpikos et al (2012) ${ }^{(12)}$ investigated the effect of impression technique and implant angulation $(0,15$, and 25 degrees) on the impression accuracy of external and internal connection implants. They concluded that impression accuracy was significantly affected only by implant angulation; impression inaccuracy was greater at the 25 degree implant angulation.

The type of impression tray used affects the impression accuracy. In general, impression trays can be categorized as custom made trays specifically for a patient or stock trays that are available in a variety of sizes from the manufacturer. ${ }^{(13,14)}$ 
The conventional plastic tray is widely used in daily clinical practice therefore, avoiding the execution of a previous impression with irreversible hydrocolloid and the construction of a customized acrylic resin tray. ${ }^{(13,14)}$

Custom resin trays have been used in elastomeric impression techniques because these materials are more accurate in uniform, thin layers of 2 to $3 \mathrm{~mm}$ thickness. Some authors have advised against the use of stock trays because the uneven bulk of the impression material is conductive to distortion. ${ }^{(14)}$ Also, the rigidity of the custom tray in comparison with the plastic stock tray does not allow distortion of the impression. ${ }^{(14,15)}$

Haselhuhn et al (2011) (16) compared the accuracy of casts obtained from a custom made open tray and a new implant tray with foil technique for multiple dental implants. They concluded that the new impression tray with the foil technique may be used as an alternative to the custom made open tray technique.

Marotti et al (2014) ${ }^{(17)}$ evaluated the accuracy of transferring implant impressions with a selfperforating impression tray. They concluded that the self-perforating (ready made) impression tray provided less accuracy than the custom made open tray.

This study aimed to evaluate the effect of implant angulation and tray type on dimensional accuracy of open tray implant impressions.

\section{MATERIALS AND METHODS}

\section{Master cast fabrication}

A unilateral free end saddle dentate acrylic maxillary model resembling Kennedy class II starting from a missing canine was used in this study. The model was duplicated by using vacuum formed thermoplastic sheet to form a negative imprint of the typodont model into which the epoxy resin was poured under vibration according to the manufacturer instructions. The epoxy resin was left for 24 hours to insure complete polymerization of the material as recommended by the manufacturer. Three epoxy resin master models were obtained for this study one for each group. To insure proper positioning of the implants, a surgical stent was used.

\section{Insertion of the implants:}

The epoxy resin master cast was held in a drilling machine with a controlled movable base. Holes matching the depth, diameter and angulation of the implants were made using straight hand piece mounted in the used drilling machine. The master cast was fixed into the table of the drilling machine at zero tilt (horizontal position) for insertion of straight implants while a sloping base was fabricated with $15^{\circ}$ and $25^{\circ}$ to be placed below the master model during the drilling of the inclined implants.

According to the direction of implants insertion, the master models were classified into three groups:

(Figure 1)

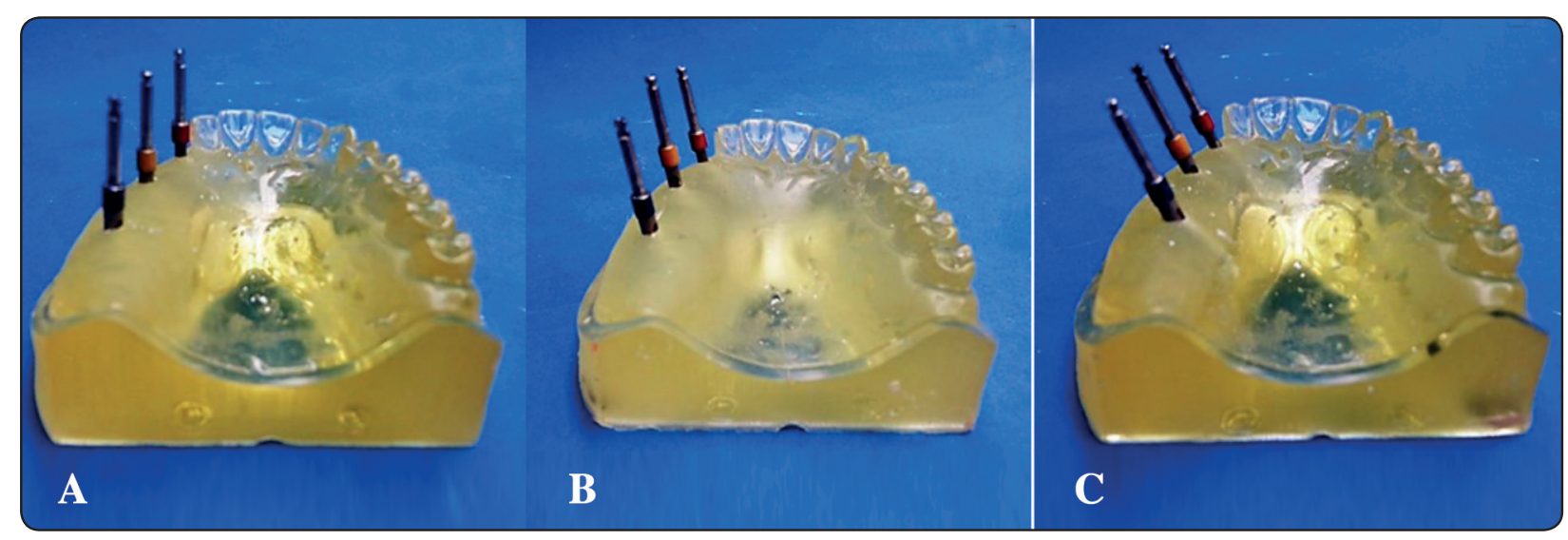

Fig. (1) Master models with surgical drills according to the direction of implants. A) $0^{\circ}$ angulation. B) $15^{\circ}$ angulation C) $25^{\circ}$ angulation. 
Group 1: The three implants were inserted with $0^{\circ}$ angulation (straight, control group).

Group 2: The three implants were inserted with $15^{\circ}$ angulation.

Group 3: The three implants were inserted with $25^{\circ}$ angulation.

Three implants were inserted in each model in the sites of the missing canine, second premolar and second molar. A $3.75 \mathrm{~mm}$ implant diameter was used for the missing canine and second premolar while a $4.5 \mathrm{~mm}$ implant was used for the second molar.

\section{Custom trays fabrication:}

Five rectangular shaped cuts were made in the land area of the master model to help orientation and complete seating of the custom trays during the impression making procedure.

Fifteen custom made trays were made using self-cured acrylic resin. Openings were created in the custom trays used for the open tray technique to accommodate for the impression transfer coping guide pins. Retention holes were made on the tray in order to retain the impression material.

\section{Impression procedure}

The open tray impression transfer copings were sandblasted with $50 \mu \mathrm{m}$ aluminum oxide particles at 2.5 bar pressure to roughen their external surface in order to enhance the retention of the impression material to the copings ${ }^{(18,19)}$. The impression transfer copings were manually tightened on the implants in the master models using the screw driver.

\section{Impression procedures using custom made trays}

The impression trays were coated with the manufacturer recommended VPS impression adhesive. Tray adhesive was applied evenly over the inner surface of each tray and extended approximately $3 \mathrm{~mm}$ onto the outer surface of the tray along the periphery ${ }^{(18,19)}$. The adhesive was allowed to dry for $15 \mathrm{~min}$ before impression. The tray adhesive was also applied to the sandblasted surfaces of the impression transfer copings ${ }^{(18,19)}$.

Using the Double mix one step technique, heavy consistency poly vinyl siloxain impression material was loaded inside the impression tray while the light consistency poly vinyl siloxain impression material was meticulously syringed around the impression copings to ensure complete coverage of the copings.

The impression trays were seated with finger pressure on the master epoxy resin models making sure that the tray reached the five cuts placed in the land area of the master model. Immediately after placing the loaded tray over the master cast, excess impression material was wiped off to verify the complete seating of each tray into the cuts. The impression material was allowed to set for 4 minutes as recommended by the manufacturer.

After complete setting of the impressions, the long pin of the impression transfer copings were unscrewed from the implant fixtures using the screw driver and the tray was removed from the master model while the impression transfer copings remained attached to the impression.

Five impressions using custom made open tray impression technique were made for each group. For each impression, implant analogs were hand tightened to the corresponding impression transfer coping using the screw driver. Silicon-based soft tissue replica was injected around the implant analogs at its junction with the impression transfer copings.

\section{Impression procedures using the ready made trays}

To insure complete seating and orientation of the ready made tray during impression making procedures, self-cured acrylic resin was used to form a rim that engaged the five rectangular cuts placed in the land area of the master model. This rim was acting as a stopper for the ready made tray flanges which were shorter than the master model flanges. 
The ready made tray is formed of panels connected to each other. The panels opposite to the impression transfer copings were removed using cotton plier. Then the trays were checked on the master model with the transfer copings to insure that they were not interfering with the tray during its insertion and removal. (Figure 2)

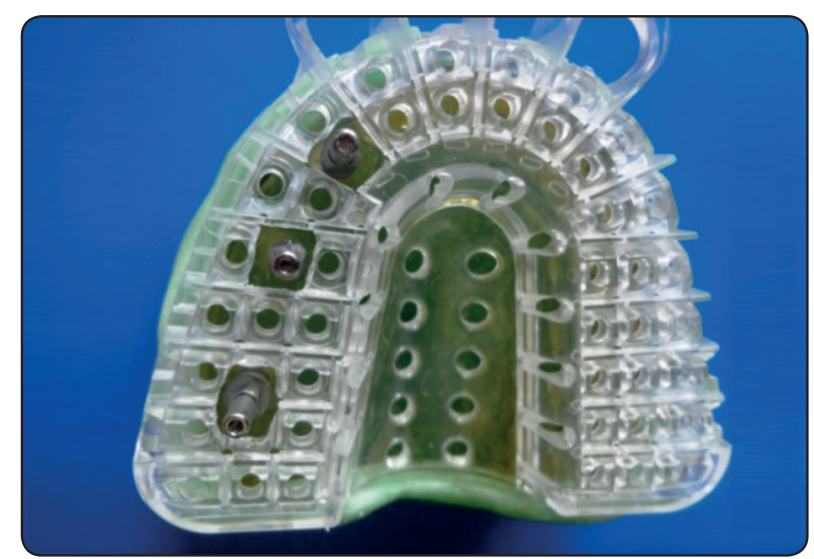

Fig. (2) The ready made tray over the master model with the transfer copings going through the openings.

Five open tray impressions using the ready made trays were made for each group. All procedures were performed as previously described for the impressions taken by the custom made trays.

\section{Impression pouring procedures}

The 30 impressions were poured with extra hard and high precision type IV die stone according to the manufacturer instructions.

\section{Preparation of the models for measurements and measurement protocol}

Titanium abutments were screwed to the implants in the master models. Straight abutments were screwed to the implants in group 1 , while $15^{\circ}$ angled abutments were screwed to the implants in group 2 and $25^{\circ}$ angled abutments were used for group 3. Notches in the mesial and distal surfaces of each abutment were made using a cutting disc to be used as a reference points during measurements. Then the notches were marked by a red marker.
The same abutments were attached to the implant analogues in the stone models in each group.

All measurements were made by a single examiner who ignored the previously described information about the code of each cast.

Dimensional accuracy of the impressions was assessed by using the travelling microscope at $30 \mathrm{X}$ magnification. The distances between the abutments in the master models were compared with the same distances on the stone casts. The dimensions of each sample were measured according to in house method of ESM (Engineering and Surface Meteorology.) NIS (National Institute for Standards).

Three interabutment distances were measured on the three epoxy master models ${ }^{(16,17)}$. (Figure 3)

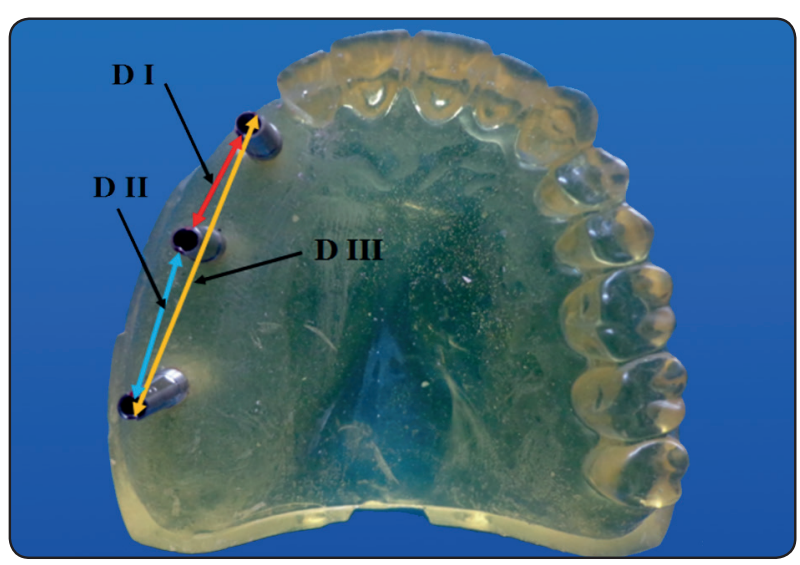

Fig. (3) Measuring distances on the master model.

1) Dimension I - The distance between the distal surface of the canine abutment and the mesial surface of the second premolar abutment (red arrow).

2) Dimension II - The distance between the distal surface of the second premolar abutment and the mesial surface of the second molar abutment (blue arrow).

3) Dimension III - The distance between the mesial surface of the canine abutment and the distal surface of the second molar abutment (yellow arrow) 
Similar distances were measured on all stone models.

\section{Statistical analysis}

Differences between master model measurements (Dimensions I, II and III) and stone model measurements represent the dimensional changes. The percentage of dimensional change was calculated as: dimensional change/master model measurement x $100^{(20-22)}$.

Quantitative data were presented as mean and standard deviation values. Data were explored for normality by checking the data distribution and calculating the mean values using KolmogorovSmirnov and Shapiro-Wilk tests.

Two way ANOVA was used to assess effect of implant angulation and tray type on dimensional changes and percentage of dimensional changes followed by pairwise comparison with Bonferroni correction.
The significance level was set at $\mathrm{P} \leq 0.05$. Statistical analysis was performed with IBM (IBM Corporation, NY, USA ) SPSS (SPSS, Inc., an IBM Company.) Statistics Version 20 for Windows.

\section{RESULTS}

Effect of implant angulation on dimensional changes and percent of dimensional changes of open tray implant impression technique

Results showed that there was no statistically significant difference in the dimensional changes and the percent of dimensional changes between the three implant angulations in dimension I. While, in dimension II and III, the results showed that there was a statistically significant difference between the three implant angulations. $25^{\circ}$ angulation showed the highest mean of dimensional change while, there was no statistically significant difference between $0^{\circ}$ and $15^{\circ}$ angulations. (Table $1 \& 2$ )

TABLE (1) Mean and standard deviation (SD) values of dimensional changes as affected by different implant angulations

\begin{tabular}{|c|c|c|c|c|c|c|c|}
\hline \multirow{2}{*}{$\begin{array}{r}\text { Implant } \\
\text { angulation }\end{array}$} & \multicolumn{2}{|c|}{$\mathbf{0}^{\circ}$} & \multicolumn{2}{c|}{$\mathbf{1 5}^{\circ}$} & \multicolumn{2}{c|}{$\mathbf{2 5}^{\circ}$} & \multirow{2}{*}{$\boldsymbol{P}$ value } \\
\cline { 2 - 8 } & Mean & SD & Mean & SD & Mean & SD & \\
\hline Dimension I & 0.1008 & 0.10029 & 0.1047 & 0.11333 & 0.1473 & 0.06611 & 0.51 \\
\hline Dimension II & 0.1304 & $0.09509^{\mathrm{a}}$ & 0.1469 & $0.1205^{\mathrm{a}}$ & 0.2520 & $0.13719^{\mathrm{b}}$ & $0.009^{*}$ \\
\hline Dimension III & 0.2619 & $0.06715^{\mathrm{a}}$ & 0.1116 & $0.14513^{\mathrm{a}}$ & 0.3295 & $0.29070^{\mathrm{b}}$ & $<0.001^{*}$ \\
\hline
\end{tabular}

TABLE (2) The mean $\%$ and standard deviation (SD) values of dimensional changes with different implant angulations

\begin{tabular}{|c|c|c|c|c|c|c|c|}
\hline \multirow{2}{*}{$\begin{array}{r}\text { Implant } \\
\text { angulation }\end{array}$} & \multicolumn{2}{|c|}{$\mathbf{0}^{\circ}$} & \multicolumn{2}{c|}{$\mathbf{1 5}^{\circ}$} & \multirow{2}{*}{ P value } \\
\cline { 2 - 8 } Dimension & Mean \% & SD & Mean \% & SD & Mean \% & SD & \\
\hline Dimension I & 0.0095 & 0.00942 & 0.0095 & 0.01030 & 0.0149 & 0.00670 & 0.326 \\
\hline Dimension II & 0.0088 & $0.00639^{\mathrm{a}}$ & 0.0112 & $0.00922^{\mathrm{a}}$ & 0.0161 & $0.00878^{\mathrm{b}}$ & $0.04^{*}$ \\
\hline Dimension III & 0.0074 & $0.00190^{\mathrm{a}}$ & 0.0033 & $0.00429^{\mathrm{a}}$ & 0.0099 & $0.00873^{\mathrm{b}}$ & $0.001^{*}$ \\
\hline
\end{tabular}


Effect of tray type on dimensional changes and percent of dimensional changes of open tray implant impression technique

Results showed insignificant difference in the dimensional changes and the percent of dimensional changes between the two tray types in dimension I and II. On the other hand, in dimensions III results showed that there was statistically significant difference in dimensional changes and the percent of dimensional changes between the two tray types. Custom made tray showed statistically significant higher dimensional changes compared to ready made tray. (Table $3 \& 4$ )

TABLE (3) Mean and standard deviation (SD) values of dimensional changes as affected by different tray types

\begin{tabular}{|c|c|c|c|c|c|}
\hline \multirow{2}{*}{ Tray type } & \multicolumn{2}{|c|}{ Custom made } & \multicolumn{2}{c|}{ Ready made } & \multirow{2}{*}{ P value } \\
\cline { 2 - 6 } Dimension & Mean & $\mathrm{SD}$ & Mean & $\mathrm{SD}$ & 0.79 \\
\hline Dimension I & 0.1224 & 0.07640 & 0.1128 & 0.11223 & 0.602 \\
\hline Dimension II & 0.1888 & 0.14917 & 0.1640 & 0.10432 & $0.019^{*}$ \\
\hline Dimension III & 0.2891 & 0.24208 & 0.1796 & 0.15329 & \\
\hline
\end{tabular}

TABLE (4): The mean $\%$ and standard deviation (SD) values of dimensional changes with different tray types

\begin{tabular}{|c|c|c|c|c|c|}
\hline \multirow{2}{*}{ Tray type } & \multicolumn{2}{|c|}{ Custom made } & \multicolumn{2}{c|}{ Ready made } & \multirow{2}{*}{ P value } \\
\cline { 2 - 5 } Dimension & Mean \% & SD & Mean \% & SD & 0.743 \\
\hline Dimension I & 0.0119 & 0.00758 & 0.0107 & 0.01049 & 0.762 \\
\hline Dimension II & 0.0125 & 0.00934 & 0.0116 & 0.00791 & $0.016^{*}$ \\
\hline Dimension III & 0.0085 & 0.00731 & 0.0052 & 0.00443 & \\
\hline
\end{tabular}

Effect of interaction between the implant angulation and tray type on dimensional changes and percent of dimensional changes of open tray implant impression technique

Results showed that with $0^{\circ}, 1^{\circ}$ and $25^{\circ}$ implant angulations, there was no statistically significant difference in dimensional changes and \% of dimensional changes between the two tray types in dimension $\mathbf{I}$.
On the other hand in dimension II and III, results showed that with $0^{\circ}$ and $15^{\circ}$ implant angulations, there was no statistically significant difference in dimensional changes and $\%$ of dimensional changes between the two tray types. While, with $\mathbf{2 5}^{\circ}$ implant angulation, results showed that there was statistically significant difference in dimensional changes and $\%$ of dimensional changes between the two tray types. Custom made tray showed higher means of dimensional changes. (Table 5\&6) 
TABLE (5) Mean and standard deviation (SD) values of dimensional changes as affected by the interaction of different implant angulations and tray types

\begin{tabular}{|c|c|c|c|c|c|c|c|c|c|c|c|c|c|c|c|}
\hline \multirow{3}{*}{ 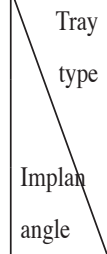 } & \multicolumn{5}{|c|}{ Dimension I } & \multicolumn{5}{|c|}{ Dimension II } & \multicolumn{5}{|c|}{ Dimension III } \\
\hline & \multicolumn{2}{|c|}{ Custom made } & \multicolumn{2}{|c|}{ Ready made } & \multirow{2}{*}{$\mathrm{p}$ value } & \multicolumn{2}{|c|}{ Custom made } & \multicolumn{2}{|c|}{ Ready made } & \multirow{2}{*}{$\mathrm{p}$ value } & \multicolumn{2}{|c|}{ Custom made } & \multicolumn{2}{|c|}{ Ready made } & \multirow{2}{*}{$\mathrm{p}$ value } \\
\hline & Mean & SD & Mean & SD & & Mean & SD & Mean & SD & & Mean & SD & Mean & SD & \\
\hline $0^{\circ}$ & 0.1053 & 0.08580 & 0.0962 & 0.12336 & 0.896 & 0.1170 & 0.10449 & 0.1438 & 0.09476 & 0.631 & 0.2266 & 0.04385 & 0.2971 & 0.07156 & 0.36 \\
\hline $15^{\circ}$ & 0.0825 & 0.07308 & 0.1269 & 0.14940 & 0.566 & 0.0758 & 0.04164 & 0.2180 & 0.13529 & $0.016^{*}$ & 0.0635 & 0.08430 & 0.1598 & 0.18572 & 0.215 \\
\hline $25^{\circ}$ & 0.1794 & 0.03617 & 0.1151 & 0.07711 & 0.13 & 0.3737 & 0.00927 & 0.1303 & 0.07236 & $<0.001 *$ & 0.5771 & 0.15462 & 0.0819 & 0.11377 & $<0.001^{*}$ \\
\hline $\mathrm{P}$ value & \multicolumn{2}{|c|}{0.104} & \multicolumn{2}{|c|}{0.921} & & \multicolumn{2}{|c|}{$<0.001 *$} & \multicolumn{2}{|c|}{0.248} & & \multicolumn{2}{|c|}{$<0.001^{*}$} & \multicolumn{2}{|c|}{$0.028 *$} & \\
\hline
\end{tabular}

TABLE (6) The mean \% and standard deviation (SD) values of dimensional changes as affected by the interaction of different implant angulations and tray types

\begin{tabular}{|c|c|c|c|c|c|c|c|c|c|c|c|c|c|c|c|}
\hline \multirow{3}{*}{$\begin{array}{l}\text { Tray } \\
\text { type } \\
\text { Implar } \\
\text { angle }\end{array}$} & \multicolumn{5}{|c|}{ Dimension I } & \multicolumn{5}{|c|}{ Dimension II } & \multicolumn{5}{|c|}{ Dimension III } \\
\hline & \multicolumn{2}{|c|}{ Custom made } & \multicolumn{2}{|c|}{ Ready made } & \multirow{2}{*}{$\mathrm{p}$ value } & \multicolumn{2}{|c|}{ Custom mil de } & \multicolumn{2}{|c|}{ Ready made } & \multirow{2}{*}{$\mathrm{p}$ value } & \multicolumn{2}{|c|}{ Custom mil de } & \multicolumn{2}{|c|}{ Ready made } & \multirow{2}{*}{$\mathrm{p}$ value } \\
\hline & Mean $\%$ & SD & Mean \% & SD & & Mean \% & SD & Mean $\%$ & SD & & Mean \% & SD & Mean \% & SD & \\
\hline $0^{\circ}$ & 0.0099 & 0.00806 & 0.0090 & 0.01159 & 0.884 & 0.0079 & 0.00702 & 0.0097 & 0.00637 & 0.649 & 0.0064 & 0.00124 & 0.0084 & 0.00203 & 0.332 \\
\hline $15^{\circ}$ & 0.0075 & 0.00664 & 0.0115 & 0.01357 & 0.492 & 0.0058 & 0.00318 & 0.0167 & 0.01035 & $0.01 *$ & 0.0019 & 0.00249 & 0.0047 & 0.00550 & 0.216 \\
\hline $25^{\circ}$ & 0.0182 & 0.00367 & 0.0117 & 0.00781 & 0.271 & 0.0239 & 0.00059 & 0.0083 & 0.00463 & $<0.001^{*}$ & 0.0173 & 0.00464 & 0.0025 & 0.00342 & $<0.001^{*}$ \\
\hline P value & & 175 & 0.8 & 78 & & & $01 *$ & & & & & $01 *$ & 0.0 & & \\
\hline
\end{tabular}

\section{DISCUSSION}

The maxillary posterior edentulous region presents many unique and challenging conditions in implant dentistry.However,existing proventreatmentmodalities make procedures in this region as predictable as in any other intraoral region. Most common surgical methods include sinus grafts to increase available bone height, onlay grafting to increase bone width and modified surgical approaches to insert implants in poorer bone density. ${ }^{(1)}$
The use of tilted implants provides a variety of advantages: facilitating placement of an implant with greater dimensions in width and height, avoiding guided bone regeneration procedures, allowing circumferential insertion of implants into bone, reduced treatment time, easier execution of procedures and reduced fees, permitting a greater number of patients to be treated because the procedure is not as restrictive as that used with straight implant abutments. ${ }^{(2)}$ 
Success in oral rehabilitation with dental implants is dependent on many factors, one being an accurate registration of those structures that constitute the basis for prosthesis support. The impression, which allows replication of these structures, must be accurate so that the resultant master cast precisely duplicates the clinical condition. ${ }^{(9)}$

The recommended VPS tray adhesive was applied to all custom and ready made trays in this study. The tray adhesive was also applied to the sandblasted surfaces of the impression transfer copings as recommended by Lahori et al ${ }^{(18,19)}$ who suggested the use of sandblasted and adhesive coated impression copings to increase the retention between the transfer copings and the impression material to achieve a more accurate and precise orientation of the implant replicas in the master casts.

In this study, the impression material used was addition silicon (poly vinyl siloxain) impression material. As the addition silicones (poly vinyl siloxain) have lower modulus of elasticity, it could be considered as a feasible alternative, particularly when non-parallel implants are present, allowing for the easy removal of the impression and reducing the permanent distortion caused by the stress between the impression material and the copings $(8,23,24,25,26)$. As described in previous studies ${ }^{(8,23,24,25,26)}$, because of the presence of a non-parallel positioning of the implants in this study, addition silicon (poly vinyl siloxain) was used.

The method selected for measuring the dimensional accuracy in this study was the relative distortion and based on making impressions for the master models using the material and technique under investigation. The dimensions of stone models poured from these impressions were then directly measured and compared with those of the master models ${ }^{(8,20,21,22,27)}$ This kind of measurement could be considered more clinically relevant than the absolute distortion, as implant supported prosthesis usually connects all the abutments to each other ${ }^{(8,21,27)}$.
A travelling microscope at $30 \mathrm{X}$ magnification was used following many researchers ${ }^{(28,29)}$ as it allowed measurement of linear distances with an accuracy of $0.001 \mathrm{~mm}(1 \mu \mathrm{m})^{(28,29)}$.

As regard the effect of implant angulation on the dimensional changes of open tray implant impression technique, results of the present study showed insignificant difference in the dimensional changes and the percent of dimensional changes between the three implant angulations in dimension I. These results were in agreement with those of Conrad et al (2007) (7) who reported similar results and found that the combined interaction of impression technique, implant angulation, and implant number had no effect on the accuracy of the duplicate casts compared to the definitive casts.

Similarly, Jo et al (2012) ${ }^{(21)}$ mentioned that the accuracy of the implant cast was not different for the parallel and $10^{\circ}$ mesial angulated groups. Also Reddy et al (2013) ${ }^{(27)}$ proofed that the combined interaction of impression material and implant angulation of $10^{\circ}$ and $15^{\circ}$ had no effect on the accuracy of the duplicate casts compared to the definitive casts.

On the other hand, the results of this study were contradicting those of Sorrentino et al (2010) ${ }^{(8)}$ who compared the accuracy of implant impressions made with different materials, lengths of impression copings, connections, and non-parallel position of the implants and found significant differences in accuracy between parallel and non-parallel implants, with $10^{\circ}$ angulation. The results are also against those of Akalin et al (2013) ${ }^{(30)}$ who reported that the models with implants placed parallel to each other exhibited greater accuracy than a model with implants placed at angles to each other when they evaluated the effects of implant angulation ( $10^{\circ}$ buccal angulation), impression material, and variation in width of the arch curvature on transfer models. 
On the other hand, in dimension II and III, the results showed that there was a significant difference in the dimensional changes and the percent of dimensional changes between the three implant angulations. $25^{\circ}$ angulation showed the highest mean of dimensional change. While, there was no significant difference between $0^{\circ}$ and $15^{\circ}$ angulation. These results were in agreement with those of $\mathbf{C a r r}$ (1992) ${ }^{(31)}$ who found insignificant difference in accuracy between $0^{\circ}$ and $15^{\circ}$ angulations when he evaluated the accuracy of working casts produced from impressions using two different transfer copings in a $15^{\circ}$ divergent two-implant posterior mandibular model.

Similarly, the results of this study were in agreement with those of Assunca o et al (2004) (32) who found that the more perpendicular the implant analog angulation in relation to the horizontal surface, the more accurate the impression when evaluating the accuracy of the transfer process with regard to implant analog angulations, impression materials, and techniques. Additionally, the results of the present study were in accordance with those of Assunca o et al (2007) (11) who revealed that perpendicular implants produced more accurate casts independently of the plaster pouring technique as they evaluated the influence of the implants inclination on the accuracy of the working cast obtained by two different pouring techniques. The results were also in accordance with those of Assunca o et al (2008) ${ }^{(33)}$ who found that there was significant differences in accuracy with $25^{\circ}$ implant divergence; inclined implants caused more inaccuracy. Additionally, Assunca o et al (2010) (34) proofed that $25^{\circ}$ and $35^{\circ}$ implant inclination may affect master cast accuracy when they compared two splinted impression transfer techniques for implant supported prosthesis with implants positioned at $0^{\circ}$, $20^{\circ}, 25^{\circ}$ and $35^{\circ}$.

The results were also in agreement with those of Rutkunas et al (2012) ${ }^{(35)}$ who found significant differences in accuracy for $25^{\circ}$ angulation; increased angulation decreased the accuracy. The results were also in accordance with the results of Mpikos et al (2012) ${ }^{(12)}$ who found that for implants with internal connections, impression accuracy was significantly affected only by implant angulation: impression inaccuracy was greater at the $25^{\circ}$ when they investigated the effect of impression technique and implant angulation $\left(0^{\circ}, 15^{\circ}, 25^{\circ}\right)$ on the impression accuracy of external and internal connection implants.

The dimensional changes occurred in this study can be attributed to the inclined implants position, because when multiple implants are placed with different angles, the distortion of the impression material on removal may increase $(8,9,23,36)$. This effect may be heightened by increasing the number of implants $(23,36)$ and the distance between the implants as the space occupied by the impression material is increased (36) leading to inaccurate impressions as occurred in dimension II and III.

Also, this alteration can be explained by the physical principle which affirms that the force applied on a body is directly proportional to the area exposed to this force. When the impression is totally covered by stone, an upper area of the angulated analog is exposed to more vertical forces in comparison to the perpendicular analog. The higher quantity of stone above the angulated analog results in a higher force than that applied above the perpendicular analog. All these forces may move the angulated analog $(11,32,33,34)$

Regarding the effect of tray type on the dimensional changes of open tray implant impression technique, results of the present study showed insignificant difference in the dimensional changes and the percent of dimensional changes between the two tray types in dimension I and II.

On the other hand, in dimensions III results showed that there was statistically significant difference in dimensional changes and the percent of dimensional changes between the two tray types. Custom made tray showed statistically significant higher dimensional changes compared to readymade tray. 
Many researchers ${ }^{(14,15,17)}$ had reported that custom made trays provide more accurate dental casts than stock trays. These findings did not agree with those of this study, which showed that the stock trays performed as well as or even better than custom made trays. These results are in agreement with those of Thongthammachat et al (2002) ${ }^{(37)}$ who stated that accurate casts can be made with either stock trays or custom trays when they evaluated the dimensional accuracy of dental casts made with different types of trays and impression materials and poured at different and multiple times. Additionally, the results were in accordance with those of Haselhuhn et al (2011) ${ }^{(16)}$ who compared the accuracy of casts obtained from a customized open tray and a new implant tray with foil technique for multiple dental implants and found that there was insignificant difference between the two impression trays and suggested that the impression tray with the foil technique may be used as an alternative to the customized open tray technique.

The superiority of the results of the ready made tray over the custom made tray in this study can be attributed to that, in case of the ready made tray, the opening made by removal of the panels were only opposite to the impression transfer copings to accommodate the impression transfer coping guide pins. On the other hand, in case of the custom made tray, the opening was opposite to the whole edentulous area. So that, this may lead to less distortion in impressions with ready made tray as the impression material between the transfer copings were supported by the tray itself.

However, the results of this study were against those of Burns et al (2003) (15) who proofed that the rigid custom trays produced significantly more accurate impressions than the polycarbonate stock trays as they studied the accuracy of open tray implant impressions comparing polycarbonate stock impression trays and rigid custom-made impression trays to make implant fixture-level impressions. The results were also contradicting those of Treml et al (2013) ${ }^{(14)}$ who found that the impressions performed with individual trays presented higher accuracy compared to the ones obtained with conventional trays.

Furthermore, the results of Marotti et al (2014) ${ }^{(17)}$ were against those of this study as they reported that the self-perforating impression tray (ready made tray) provided less accuracy than the custom made open tray when they evaluated the accuracy of transferring implant impression technique.

This study had some limitations; one being in vitro study as all impressions were taken under ideal conditions without the presence of soft tissues, blood, saliva and sulcular fluid which may affect the accuracy of the impressions. Moreover, the results of the present study were limited to a number of three implants in a partially edentulous model and may not be relevant for impressions made in the presence of higher number of implants or implants inserted in completely edentulous cases.

Further clinical investigations will be necessary to confirm the results of the present in vitro study.

\section{CONCLUSIONS}

Within the limitations of this in vitro study, the following conclusions could be drawn:

1) Implant angulation had a significant effect on the dimensional accuracy of open tray implant impression technique regardless of the tray type in case of $25^{\circ}$ angulated implants.

2) Tray type had a significant effect on the dimensional accuracy of open tray implant impression technique only with dimension III where custom made tray showed higher dimensional changes compared to ready-made tray.

3) Impressions with ready-made trays showed less dimensional changes in case of $25^{\circ}$ angulated implants. 


\section{REFERENCES}

1. Misch C: Contemporary Implant Dentistry. Available bone and dental treatment plan. $3^{\text {rd }}$ eds. St. Louis, Mo.: Mosby/ Elsevier. 2008; pp: 3-25.

2. Cavallaro J and Greenstein G: Angled Implant Abutments: A Practical Application of Available Knowledge. J Am Dent Assoc 2011; 142: 150-158.

3. Buser D, Dahlin C and Schenk Pk: Guided bone regeneration in implant dentistry. $1^{\text {st }}$ eds. Quintessence, 1994; pp: 13-29.

4. Aparicio C, Perales P and Rangert B: Tilted Implants as an Alternative to Maxillary Sinus Grafting: A Clinical, Radiograghic, and Periotest Study. Clin Implant Relat Res. 2001; 3: 39-49.

5. Kurtulmus-Yilmaz S, Ozan O, Ozcelik T and Yagiz A: Digital evaluation of the accuracy of impression techniques and materials in angulated implants. J Dent. 2014; 42: 1551-1559.

6. Ma J and1 Rubenstein J: Complete arch implant impression technique. J Prosthet Dent. 2012; 107: 405-410.

7. Conrad H, Pesun I, DeLong R and Hodges J: Accuracy of two Impression techniques with angulated implants. J Prosthet Dent 2007; 97: 349-356.

8. Sorrentino R, Gherlone E, Calesini G and Zarone F: Effect of Implant Angulation, Connection Length, and Impression Material on the Dimensional Accuracy of Implant Impressions. An In Vitro Comparative Study. Clin. Oral Impl Res. 2010; 12: 63-76.

9. Kempler J: The Effect of Impression Technique, Connection Type and Implant Angulation on Impression Accuracy. M.Sc. Thesis, University of Maryland, 2011.

10. Lee H, Joseph S, Hochstedler J and Ercoli C: The accuracy of implant impressions: A systematic review. J Prosthet Dent 2008; 100: 285-291.

11. Assunção W, Delben J, Gomes É, Barão V and Jorge J: Influence of the implants inclination on the accuracy of the working cast. Cienc Odontol Bras 2007; 10: 16-24.

12. Mpikos P, Tortopidis D, Galanis C, Kaisarlis G and Koidis $\mathrm{P}$ : The effect of impression technique and implant angulation on the impression accuracy of external- and internalconnection implants. Int J Oral Maxillofac Implants. 2012; 27: 1422-1428.
13. Cho G and Chee W: Distortion of disposable plastic stock trays when used with putty vinyl polysiloxane impression materials. J Prosthet Dent. 2004; 92: 354-8.

14. Treml A, Galvao G, Giovanini A, Caregnatto de Morais E, Gonzaga C and Marcos da Silva E: Comparative evaluation of the accuracy of pick-up transfer impressions performed with two different types of trays. RSBO. 2013; 10 : 128-134.

15. Burns J, Palmer R, Howe L and Wilson R: Accuracy of open tray implant impressions: an in vitro comparison of stock versus custom trays. J Prosthet Dent. 2003; 89: 250255.

16. Haselhuhn K, Papoulia K and Wolfart S: Accuracy Of Multiple Implant Impressions: A New Impression Tray. Implantologie 2011; 18:441-449.

17. Marotti J, Tortamano P, Castilho T, Steagall W, Wolfart S and Haselhuhn K: Accuracy of a self-perforating impression tray for dental implants. J Prosthet Dent. 2014; 112: 843-848.

18. Lahori M, Mahesh L, Nagrath R and Singh S: An Evaluation of the Accuracy of Multiple Implant Impression Techniques: An in Vitro Study. J Implant Adv Clin Dent. 2012; 4: 57-69.

19. Lahori M, Nagrath R and Agrawal P: An In Vitro Study to Compare the Accuracy of the Master Cast Fabricated by Four Different Transfer Impression Techniques or SingleTooth Implant Replacement. J Indian Prosthodont Soc. 2014; 14: 78-84.

20. Walker M, Ries D and Borello B: Implant cast accuracy as a function of impression techniques and impression material viscosity. Int J Oral Maxillofac Implants. 2008; 23: 669-674.

21. Jo SH, Kim K, Seo JM, Song KY, Park JM and Ahn SG: Effect of impression coping and implant angulation on the accuracy of implant impressions: an in vitro study. J Adv Prosthodont 2010; 2: 128-33.

22. Pereira J, Murata K, do Valle A, Ghizoni J and Shiratori F: Linear dimensional changes in plaster die models using different elastomeric materials. Braz Oral Res. 2010; 24: 336-41.

23. Akalin Z, Ozkan Y, Ekerim A: Effects of implant angulation, impression material, and variation in arch curvature width on implant transfer model accuracy. Int J Oral Maxillofac Implants. 2013; 28: 149-157. 
24. Alikhasi M, Siadat H and Rahimian S: The Effect of Implant Angulation on the Transfer Accuracy of ExternalConnection Implants. Clin Implant Relat Res. 2014; 1: 1-8.

25. Berg J, Johnson G, Lepe X and Adán-Plaza S: Temperature effects on the rheological properties of current polyether and polysiloxane impression materials during setting. $\mathrm{J}$ Prosthet Dent. 2003; 90: 150-161.

26. Lu H, Nguyen B and Powers J: Mechanical properties of 3 hydrophilic addition silicone and polyether elastomeric impression materials. J Prosthet Dent. 2004; 92:151-154.

27. Reddy S, Prasad K, Vakil H, Jain A and Chowdhary R: Accuracy of impressions with different impression materials in angulated implants. Nig J Clin Pract. 2013; 16: 279-284.

28. Wee A: Comparison of impression materials for direct multiimplant impressions. J Prosthet Dent. 2000; 83: 323-31.

29. Stober T, Johnson G and Schmitter M: Accuracy of the newly formulated vinyl siloxanether elastomeric impression material. J Prosthet Dent. 2010; 103: 228-239.

30. Akalin Z, Ozkan Y, Ekerim A: Effects of implant angulation, impression material, and variation in arch curvature width on implant transfer model accuracy. Int J Oral Maxillofac Implants. 2013; 28: 149-157.

31. Carr A: Comparison of impression techniques for a twoimplant 15-degree divergent model. Int J Oral Maxillofac
Implants. 1992, 7: 468-475.

32. Assunção W, Gennari Filho H and Zaniquelli O: Evaluation of transfer impressions for osseointegrated implants at various angulations. Implant Dent. 2004; 13: 358-366.

33. Assunção W, Cardoso A, Gomes E, Tabata L and dos Santos P: Accuracy of impression techniques for implants. Part 1- influence of transfer copings surface abrasion. J Prosthodont. 2008; 17: 641-647.

34. Assunção WG, Britto RC, Barão VAR, Delben JA and Henrique dos Santos P: Evaluation of Impression Accuracy for Implant at Various Angulations. Implant Dent 2010; 19: 167-174.

35. Rutkunas V, Sveikata K and Savickas R: Effects of Implant Angulation, Material Selection, and Impression Technique on Impression Accuracy: A Preliminary Laboratory Study. Int J Prosthodont. 2012; 25: 512-515.

36. Prithviraj D, Pujari M, Garg P and Shruthi D: Accuracy of the implant impression obtained from different impression materials and techniques: review. J Clin Exp Dent. 2011; 3: 106-111.

37. Thongthammachat S, Moore K, Barco M, Hovijitra S, Brown D and Andres C: Dimensional Accuracy of Dental Casts, influence of Tray Material, Impression Material, and Time. J Prosthodont. 2002; 11: 98-108. 